\title{
Silencing of ATM expression by siRNA technique contributes to glioma stem cell radiosensitivity in vitro and in vivo
}

\author{
YAN LI ${ }^{1}$, LUCHUN LI ${ }^{1}$, ZHIJUAN WU ${ }^{1}$, LULU WANG ${ }^{1}$, YONGZHONG WU ${ }^{2}$, DAIRONG LI ${ }^{1}$, \\ UIWEN MA ${ }^{1}$, JIANGHE SHAO ${ }^{1}$, HUIQING YU ${ }^{1}$ and DONGLIN WANG ${ }^{1}$ \\ Departments of ${ }^{1}$ Oncology and ${ }^{2}$ Radiotherapy, Chongqing Cancer Institute, Chongqing 400030, P.R. China
}

Received August 25, 2016; Accepted October 21, 2016

DOI: 10.3892/or.2017.5665

\begin{abstract}
Evidence has shown that both high expression of the ataxia-telangiectasia mutated (ATM) gene and glioma stem cells (GSCs) are responsible for radioresistance in glioma. Thus, we hypothesized that brain tumor radiosensitivity may be enhanced via silencing of the ATM gene in GSCs. In the present study we successfully induced GSCs from two cell lines and used CD133 and nestin to identify GSCs. A lentivirus was used to deliver siRNA-ATM ${ }^{\text {Puro }}$ (A group) to GSCs prior to radiation, while siRNA-HK ${ }^{\text {Puro }}$ ( $\mathrm{N}$ group) and GSCs (C group) were used as negative and blank controls, respectively. RT-qPCR and western blotting were performed to verify the efficiency of the siRNA-ATM technique. The expression of the ATM gene and ATM protein were significantly downregulated post-transfection. Cell Counting Kit-8 (CCK-8) and colony formation assays revealed that the A group demonstrated weak cell proliferation and lower survival fractions post-irradiation compared to the $\mathrm{C} / \mathrm{N}$ groups. Flow cytometry was used to examine the percentage of cell apoptosis and $\mathrm{G} 2$ phase arrest, which were both higher in the A group than in the $\mathrm{C} / \mathrm{N}$ groups. We found that the comet tail percentage evaluated by comet assay was higher in the $\mathrm{A}$ group than in the $\mathrm{C} / \mathrm{N}$ groups. After radiation treatment, three radiosensitive genes [p53, proliferating cell nuclear antigen (PCNA), survivin] exhibited a decreasing tendency as determined by RT-qPCR. Mice underwent subcutaneous implantation, followed by radiation, and the resulting necrosis and hemorrhage were more obvious in the A group than in the $\mathrm{N}$ groups. In conclusion, silencing of $A T M$ via the siRNA technique improved radiosensitivity of GSCs both in vitro and in vivo.
\end{abstract}

\section{Introduction}

Glioma is a malignant brain tumor that unsatisfactorily responds to therapy. Despite some limited advances in

Correspondence to: Dr Donglin Wang, Department of Oncology, Chongqing Cancer Institute, Chongqing 400030, P.R. China E-mail: xiaolianbei@sina.com

Key words: glioma stem cells, ATM, siRNA, radiosensitivity, animal model surgical, radiotherapeutic and chemotherapeutic protocols, the average life expectancy of patients with glioblastoma remains only $12-15$ months $(1,2)$.

It has been reported that cancer stem cells (CSCs), which constitute a small proportion of tumors, play an important role in tumor recurrence and metastasis $(3,4)$. In recent years, increasing evidence has shown that glioma stem cells (GSCs) are related to radioresistance. Zhou et al (5) compared the biological characteristics of glioma cells (GCs) and GSCs using comet tail assays, colony formation and apoptosis percentages, among other techniques. They found that GSCs were more resistant than GCs at the same X-ray irradiation dosage. Various scholars believe that constitutive activation of the DNA damage response may be a major mechanism of GSC resistance (2).

The ataxia-telangiectasia mutated (ATM) protein belongs to the PI3K family and functions as a proximal component of DNA damage-induced cell cycle checkpoint pathways. The ATM gene plays an indispensable role in the DNA double-strand break (DSB) impairment induced by ionizing irradiation $(6,7)$.

Increasing studies have shown that high ATM expression in glioma results in radioresistance (2,8-10). GSCs are also associated to radioresistance, thus, we aimed to determine whether ATM exhibited a high expression in GSCs and contributed to radioresistance (11). In our previous study, radioresistance in both GCs and GSCs was found to be linked to a high expression of the ATM gene (5).

Numerous scholars presently have contributed insight to radiosensitivity in glioma cells through the silencing of the ATM gene via gene interference or drug inhibition. The usual strategy of gene interference employs small interfering RNA (siRNA) to deliver a silencing gene using a lentivirus system (12-14). Pharmacological treatment primarily consists of an ATM kinase inhibitor (KU55933 and KU60019) $(8,15)$. Although, the two methods have different inference paths and efficiencies, both can suppress or silence the ATM gene.

To the best of our knowledge, no research on silencing the ATM gene in GSCs either in vitro or in vivo has been reported. In the present study, we mirrored the strategy of GC sensitization to observe whether siRNA-ATM contributed to GSC radiosensitivity. The results of the present study may provide new clues for enhancing the effectiveness of glioma treatment. 


\section{Materials and methods}

Cell lines. Human glioma cell lines U251 and A172 were used in the present study. The U251 cell line was gifted by the Central Laboratory of Oncology Department of Xinqiao Hospital of The Third Military Medical University (Chongqing, China). The A172 cell line was purchased from the Centre of Cell Cultures of the Chinese Academy of Medical Sciences (Shanghai, China). All cell lines were cultured in RPMI-1640 medium supplemented with $10 \%$ fetal calf serum (FCS) (both from Gibco, Grand Island, NY, USA), $100 \mathrm{U} / \mathrm{ml}$ penicillin, $100 \mu \mathrm{g} / \mathrm{ml}$ streptomycin, $2 \mathrm{mM}$ glutamine and $1 \mathrm{mM}$ sodium pyruvate.

In addition, both cell lines were then cultured in neural stem cell medium (NSC-M) to induce GSCs. The medium was supplemented with $20 \mathrm{ng} / \mathrm{ml}$ basic fibroblast growth factor (bFGF), $20 \mathrm{ng} / \mathrm{ml}$ epidermal growth factor (EGF) (both from PeproTech, Inc., Rocky Hill, NJ, USA), 10 ng/ml leukemia inhibitory factor (LIF; Chemicon, Temecula, CA, USA), and a 1:50 dilution of B27 (Gibco-BRL, Carlsbad, CA, USA).

The GCs and GSCs were cultured in humidified incubators at $37^{\circ} \mathrm{C}$ in an atmosphere with $5 \% \mathrm{CO}_{2}$. The cells were maintained by serial passaging after trypsinization with $0.1 \%$ trypsin (Gibco).

Animals. Four-week-old male BALB/c nu-nu mice weighing $20 \mathrm{~g}$ each were purchased from the Shanghai Experimental Animal Center of the Chinese Academy of Medical Sciences (Shanghai, China). They were maintained in a pathogen-free environment at $25-27^{\circ} \mathrm{C}$ and $45-50 \%$ humidity, and supplied with food and water ad libitum. All of the mice were humanely treated according to the Institutional Policies on Human Care and Use of Laboratory Animals. The animal experiment in the present study, was approved by the Ethics Committee of Chongqing Cancer Institute.

Induction and identification of GSCs. Cells were seeded into 6-well plates and cultured in NSC-M medium that was partially changed every two days. At three to five days of culture, large tumor balls had formed that were considered GSCs, at which point the passages were performed weekly. The passage procedure was the same as the general cell culture.

The tumor balls were identified as GSCs using the double-labeling immunofluorescence technique. GSCs were collected by centrifugation, and single-cell suspensions were plated into $24-w e l l$ plates at a density of $2 \times 10^{5} / \mathrm{ml}$ after sterile coverslips were installed under the bottom of each well. NSC-M was supplemented into the plates and GSC tumor spheres were formed after five days of culture. The cells were then washed three times with phosphate-buffered saline (PBS) for 5 min each and fixed with $4 \%$ polyoxymethylene for 30 min. After three additional PBS washes, $0.5 \%$ Triton X-100 was added into the wells, followed by the addition of $10 \%$ FBS and $50 \mu 1$ of CD133 (Miltenyi Biotec, Inc., Auburn, CA, USA) and nestin (Abcam, Cambridge, MA, USA) antibodies for the immunoreaction. The aforementioned medium was co-incubated at $4^{\circ} \mathrm{C}$ for $12 \mathrm{~h}$. After another three PBS washes, the secondary antibodies (TRITC and FITC; R\&D Systems, Inc., Minneapolis, MN, USA) were added and incubated at $37^{\circ} \mathrm{C}$ for $1 \mathrm{~h}$. After a final three PBS washes, 4',6-diamidino-2-phenylindole (DAPI) (Beyotime Institute of Biotechnology, Shanghai, China) staining reagent was added and the immunoreactivity was observed under laser confocal microscope (SP5; Leica, Mannheim, Germany).

Cell transfection by siRNA-ATM lentivirus and radiation treatment in vitro. Due to economic usage of the virus drop, targeted GSCs were created via transfection followed by induction. Two cell lines were seeded into 6-well plates at a density of $2 \times 10^{5}$ cells $/ \mathrm{ml}$, respectively. After $48 \mathrm{~h}$ of culture, $40 \mu 1$ (MOI=2) of siRNA-ATM ${ }^{\text {Puro }}$ or siRNA-HK ${ }^{\text {Puro }}$ lentivirus (Hanheng Bio Co. Ltd., Shanghai, China) was added to the plates when the cells achieved $\sim 40 \%$ confluence. Subsequently, the medium was replaced by serum-free medium for $24 \mathrm{~h}$ of co-culture. An inverted fluorescence microscope was used to observe the transfection efficiency, and treatment with puromycin was performed to select tolerant target cells until a stable cell line transfected with the lentivirus was successfully established. The GSCs of the two transfected cell lines was induced as aforementioned.

Three groups of GSCs from each cell line were designed in the in vitro experiments: blank control group C (U251 and A172 cells not transfected with siRNA), negative control group N (U251 and A172 cells transfected with siRNA-HK ${ }^{\text {Puro }}$ ), and experimental group A (U251 and A172 cells transfected with siRNA-ATM ${ }^{\text {Puro }}$ ). The GSCs from the three groups were irradiated using a 6-MV X Rad source (SN4474; Varian Medical Systems, Palo Alto, CA, USA) to deliver doses of 2, 4, 6 and 8 Gy (colony forming assay) and 5 Gy (all other assays in vitro). The dose rate was $300 \mathrm{cGy} / \mathrm{min}$. The cells were harvested after irradiation at different time-points: cells for RT-qPCR and western blotting were harvested $24 \mathrm{~h}$ after irradiation; cells for the comet assay were harvested after $4 \mathrm{~h}$; and cells for flow cytometric analysis were harvested after $24 \mathrm{~h}$.

Animal model construction and radiotherapy in vivo. GSCs from the two cell lines in good condition into which siRNAATM $^{\text {Puro }}$ or siRNA-HK ${ }^{\text {Puro }}$ was transfected were collected and injected into two flanks of haunch of the same mouse, respectively. After 2-3 weeks, the tumor volume reached $1.5 \times 1.3 \times 1.1 \mathrm{~cm}$, and the irradiation was performed.

The mice of each group (siRNA-ATM ${ }^{\text {Puro }}$ and siRNAHK $^{\text {Puro }}$ ) were divided into two subgroups (irradiation and radiation-free) of three animals each after the subcutaneous transplantation. The mice from the two radiation subgroups $(\mathrm{n}=6)$ were administered ketamine $(10 \mathrm{ml} / \mathrm{kg})$ and fixed in the ventricumbent position. The subcutaneous tumor was subsequently locally irradiated under a 6-MV linear accelerator. The radiotherapy parameters were as follows: target range, $100 \mathrm{~cm}$; dose rate, $300 \mathrm{MU} / \mathrm{min}$; and total dose, 1,500 cGy. Three weeks later, all of the mice were sacrificed to enable histopathological examination of the tumors. The samples were fixed in $10 \%$ formalin for paraffin-embedding and stained with hematoxylin and eosin for microscopic examination.

Reverse transcription quantitative polymerase chain reaction (RT-PCR). Total RNA of GSCs from the two cell lines was extracted using TRIzol reagent (Sigma-Aldrich, Milwaukee, WI, USA) according to the manufacturer's 
Table I. Sequences of the primers used for RT-qPCR.

\begin{tabular}{|c|c|c|c|c|}
\hline Gene & & Primer sequence & Annealing temperature $\left({ }^{\circ} \mathrm{C}\right)$ & Product length $(\mathrm{bp})$ \\
\hline \multirow[t]{2}{*}{ Actin } & $\mathrm{F}$ & 5'-TGACGTGGACATCCGCAAAG-3' & 60 & 205 \\
\hline & $\mathrm{R}$ & 5'-CTGGAAGGTGGACAGCGAGG-3' & & \\
\hline \multirow[t]{2}{*}{ ATM } & $\mathrm{F}$ & 5'-GCACAGAAGTGCCTCCAATTC-3' & 60 & 125 \\
\hline & $\mathrm{R}$ & 5'-ACATTCTGGCACGCTTTGG-3' & & \\
\hline \multirow[t]{2}{*}{ P53 } & $\mathrm{F}$ & 5'-CAGTCTACCTCCCGCCATAA-3' & 57 & 144 \\
\hline & $\mathrm{R}$ & 5'-GTTCAAAGACCCAAAACCCA-3' & & \\
\hline \multirow[t]{2}{*}{ PCNA } & $\mathrm{F}$ & 5'-GGGACACTGCTGGTGGTATT-3' & 59 & 102 \\
\hline & $\mathrm{R}$ & 5'-ACTGGTGGAGGGTAAACGGA-3' & & \\
\hline \multirow[t]{2}{*}{ Survivin } & $\mathrm{F}$ & 5'-TGTGATGAGGACAAAACGAAGC-3' & 59 & 100 \\
\hline & $\mathrm{R}$ & 5'-CAGCCTGAGCAACAGAGCAA-3' & & \\
\hline
\end{tabular}

ATM, ataxia-telangiectasia mutated; PCNA, proliferating cell nuclear antigen.

protocol. The concentration and purity were evaluated by an ultraviolet spectrophotometer, and the RNA of the two cell lines was reverse transcribed into cDNA using a reverse transcription kit (Takara, Dalian, China). A master mix (20 $\mu 1$ in total) was prepared on ice including $5 \mathrm{X}$ PrimeScript buffer $(4 \mu \mathrm{l})$, PrimeScript RT Enemy $(1 \mu \mathrm{l}), 6 \mathrm{~N}$ random 6 $(1 \mu \mathrm{l})$, total RNA (500 ng) and nuclease-free water $(14 \mu \mathrm{l})$. The reaction was carried out at $37^{\circ} \mathrm{C}$ for $30 \mathrm{~min}$, then $85^{\circ} \mathrm{C}$ for $5 \mathrm{sec}$, and $4^{\circ} \mathrm{C}$, thereafter. Next, cDNA from the GSCs was subjected to RT-qPCR, which was performed using the IQ5 PCR Instrument and the SYBR-Green Real-Time PCR Master Mix kit (Takara). To amplify the ATM, a master mix (25 $\mu \mathrm{l})$ was prepared on ice with $10 \mu \mathrm{l}$ of SYBR-Green I Master Mix, $1 \mu \mathrm{l}$ of each primer, $5 \mu \mathrm{l}$ of cDNA, and $8 \mu 1$ of nuclease-free water. The cDNA was initially denatured at $95^{\circ} \mathrm{C}$ for $30 \mathrm{sec}$, followed by 40 cycles of denaturation at $95^{\circ} \mathrm{C}$ for $5 \mathrm{sec}$, annealing at $60^{\circ} \mathrm{C}$ for $30 \mathrm{sec}$, and extension at $72^{\circ} \mathrm{C}$ for $40 \mathrm{sec}$. The experiments were repeated in triplicate.

Primer sequences were designed by Software Primer 5.0, and are listed in Table I. Actin was considered an endogenous control. A melting curve analysis was performed to confirm the specificity of the amplification and absence of primer dimers for each run. Relative quantification of $A T M$ gene expression was performed using the $2^{-\Delta \Delta C t}$ method.

Western blotting. GSCs of the U251 and A172 cells were harvested on ice following the use of a total protein extraction kit containing a protease inhibitor. The total protein was extracted from each cell line after homogenization, and the protein concentration was assessed using Coomassie Brilliant Blue staining. Sodium dodecyl sulfate-polyacrylamide gel electrophoresis (SDS-PAGE) $(10 \%)$ was then used to separate the proteins ( $50 \mathrm{mg}$ of protein/sample) that were transferred onto a polyvinylidene fluoride membrane. The membrane was incubated overnight with the primary antibodies diluted to 1:1,000 (5\% w/v bovine serum albumin using Tris-buffered saline/Tween-20) and then incubated with secondary antibodies diluted to 1:3,000 (Zhongshan Biotechnology, Beijing, China). Subsequently, the treated membrane was subjected to film development and further analysis. The primary antibodies consisted of anti-ATM and anti-phosph-ATM (S1981) antibodies (Santa Cruz Biotechnology Inc., Santa Cruz, CA, USA).

Cell Counting Kit-8 (CCK-8). After irradiation, the cell proliferation ability of the GSCs was detected using the CCK-8 assay (Dojindo, Kumamoto, Japan). Single-cell suspensions of GSCs from the two cell lines, including those transfected with siRNA-ATM ${ }^{\text {Puro }}$ or siRNA-HK ${ }^{\text {Puro }}$, were plated into 96-well plates at a concentration of 1,000 cells/well, and cultured overnight at $37^{\circ} \mathrm{C}$ in NSC-M medium. The cells were then incubated with $10 \mu \mathrm{l}$ of CCK- 8 for $4 \mathrm{~h}$ without removal of the medium and the plates were shaken for $15 \mathrm{~min}$. Finally, the absorbance was detected within the range of 490-630 nm with an enzyme-linked immunosorbent assay reader (ELX800; BioTek Instruments, Inc., Winooski, VT, USA).

Cell cycle phase and cell apoptosis analyses by flow cytometry. The percentage of cell distribution in the various phases of the cell cycle was determined by flow cytometry. After radiation, single-cell suspensions of U251 and A172 GSCs $\left(1 \times 10^{5}\right.$ cells $\left./ \mathrm{ml}\right)$ including transfected cells were washed twice with PBS and fixed in $75 \%$ alcohol. After treatment with $500 \mu \mathrm{l}$ of $1 \mathrm{~g} / 1 \mathrm{RNase}$ at $37^{\circ} \mathrm{C}$ for $30 \mathrm{~min}$, the cells were collected, fixed again and then stained with propidium iodide (PI) for the flow cytometric analysis. The percentage of cells that underwent cell apoptosis was also detected using flow cytometry. Treated with radiation, single-cell suspensions of GSCs $\left(1 \times 10^{5}\right.$ cells $\left./ \mathrm{ml} ; 100 \mu \mathrm{l}\right)$ including transfected cells were added into microcentrifuge tubes, and then mixed with $5 \mu 1$ of Annexin IV-PE. After incubation at room temperature for $15 \mathrm{~min}$, the percentage of apoptotic cells was analyzed using flow cytometry.

Clonogenic survival assay. The cell survival fraction was determined by a standard colony-forming efficiency assay. Briefly, U251 and A172 GSCs or transfected cells were disaggregated into a single-cell suspension and diluted to a final concentration of $2 \times 10^{3}$ cells $/ \mathrm{ml}$. The cells were then plated into 6 -well plates, cultured overnight at $37^{\circ} \mathrm{C}$, and subjected to irradiation at doses of 2, 4, 6 and $8 \mathrm{~Gy}$. After 


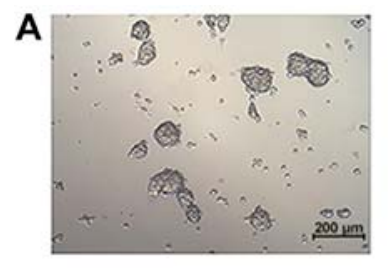

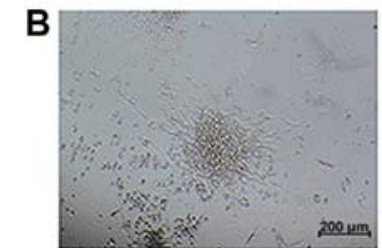

Before

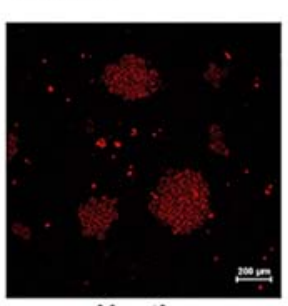

Nestin

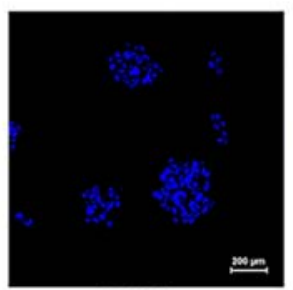

DAPI

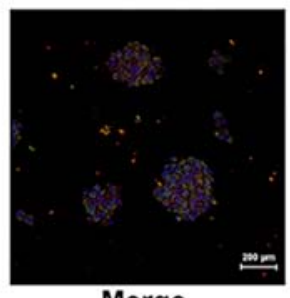

Merge

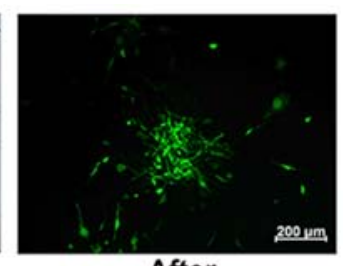

After

Figure 1. Induction and identification of glioma stem cells (GSCs) from the U251 and A172 cell lines. (A) GSCs induced and cultured in serum-free neural stem cell medium revealed under light microscopy. (B) Transfected GSCs showing a high efficiency of transfection. (C) Double-labeling immunofluorescence revealing the expression of CD133 and nestin in GSCs.
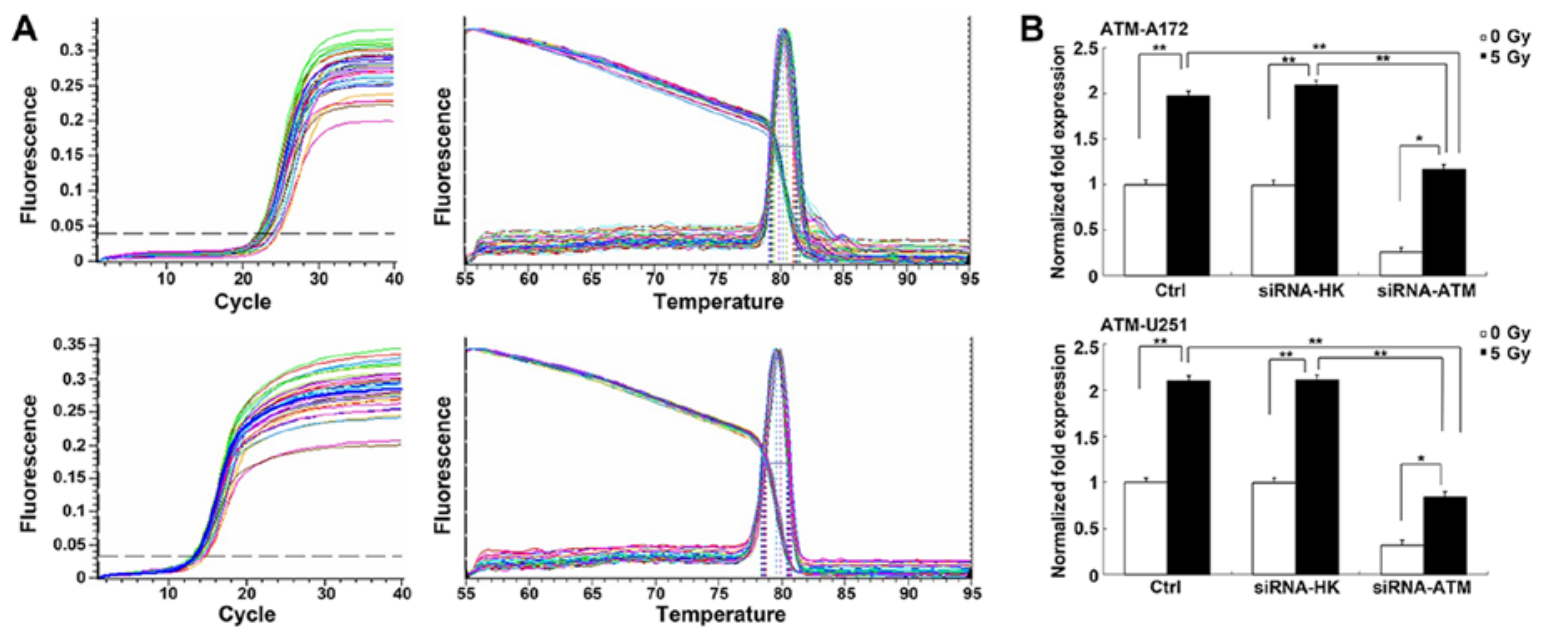

Figure 2. Ataxia-telangiectasia mutated (ATM) expression after small interfering RNA (siRNA) treatment in U251 and A172 glioma stem cells by reverse transcription quantitative polymerase chain reaction (RT-PCR). (A) Amplification and melting curve analysis confirming specificity. (B) After 5 Gy of irradiation, the gene expression in the A group was considerably lower than those in the $\mathrm{N}$ and $\mathrm{C}$ groups. There was no difference between the $\mathrm{A}$ group and the $\mathrm{C}$ or $\mathrm{N}$ groups before radiation treatment. All of the experiments were repeated in triplicate. Data were analyzed using analysis of variance (ANOVA) and are presented as the mean $\pm \mathrm{SD}$; ${ }^{\mathrm{P}}<0.05,{ }^{* *} \mathrm{P}<0.01$. A, siRNA-ATM ${ }^{\text {Puro }}$ lentivirus; $\mathrm{C}$, blank control; $\mathrm{N}$, siRNA-HK ${ }^{\text {Puro }}$ lentivirus.

radiation treatment, all of the plates were incubated at $37^{\circ} \mathrm{C}$ in a $5 \% \mathrm{CO}_{2}$ atmosphere for two weeks. The cells were washed with PBS, fixed with formalin, stained with crystal violet $(0.1 \% \mathrm{w} / \mathrm{v})$, rinsed with $\mathrm{dH}_{2} \mathrm{O}$ and finally dried. Colonies that contained $>50$ cells upon microscopic examination were considered surviving colonies. The formula used was as follows: Colony formation rate $(\mathrm{PE})=$ colony number/cell plating number $x 100 \%$; and survival fraction $(\mathrm{SF})=$ number of colonies that formed in response to a certain dose/cell plating number x PE. After data analysis, the cell survival curve was drawn using GraphPad Prism 5.0 software. The experiments were performed in triplicate.

Single-cell gel electrophoresis (neutral comet assay). The single-cell gel electrophoresis assay was performed using the comet assay kit (Trevigen, Gaithersburg, MD, USA) according to the manufacturer's instructions. Briefly, $4 \mathrm{~h}$ after X-ray irradiation, single-cell suspensions of U251 and A172 GSCs including transfected cells were washed with PBS and mixed with low-melting agarose (1:10). Thereafter, the cell-agarose 

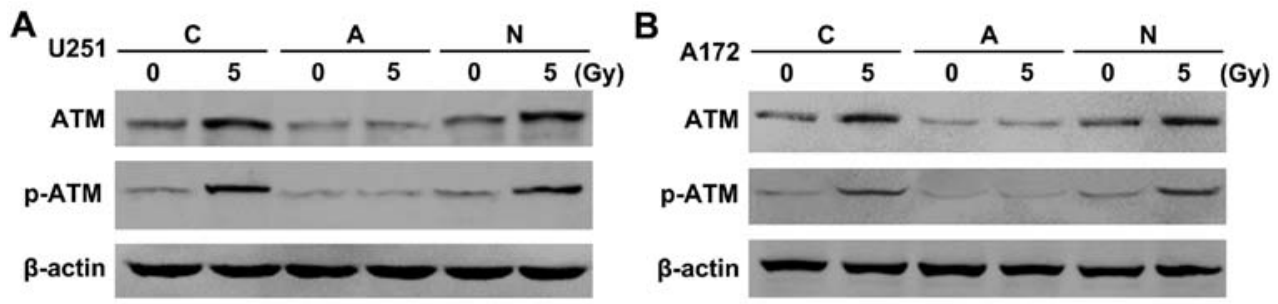

Figure 3. Expression of ataxia-telangiectasia mutated (ATM) and p-ATM (phosphorylated-ATM; S1981) after small interfering RNA (siRNA)-mediated treatment in glioma stem cells by western blotting. Total ATM protein expression in the A group was partly downregulated compared with those of the C and $\mathrm{N}$ groups when a dose of $5 \mathrm{~Gy}$ was delivered. However, the expression of the p-ATM protein in the A group was significantly decreased compared with the other groups after irradiation. In contrast, the expression of ATM and p-ATM (S1981) in the C and N groups were higher after irradiation than before. (A) ATM protein expression in U251 glioma stem cells. (B) ATM protein expression in A172 glioma stem cells.

A

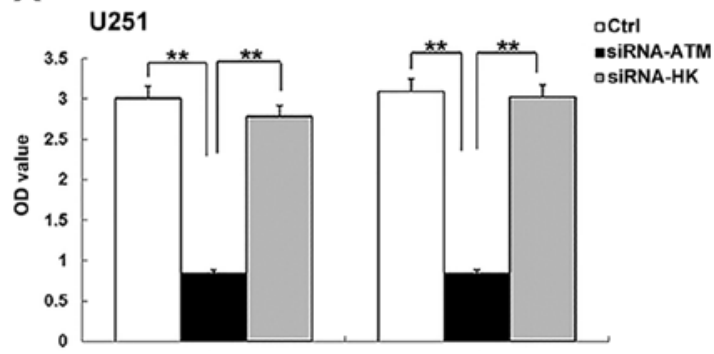

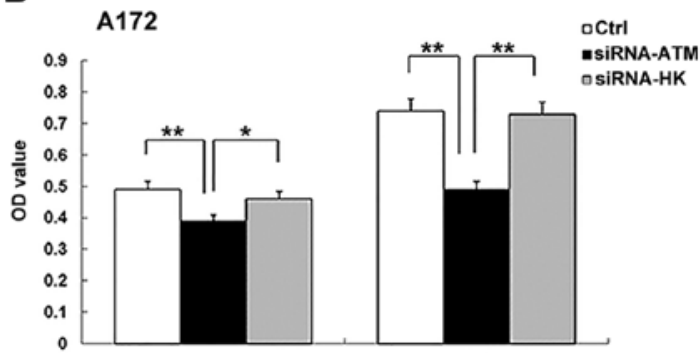

Figure 4. Cell proliferation is inhibited after small interfering RNA-ataxia-telangiectasia mutated (siRNA-ATM) treatment in the U251 and A172 glioma stem cells. At 48 and $72 \mathrm{~h}$ post-irradiation, cell proliferation in the A group was considerably decreased compared with those in the C and $\mathrm{N}$ groups. (A) Data in U251 glioma stem cells. (B) Data in A172 glioma stem cells. All of the experiments were repeated in triplicate. The data were analyzed using analysis of variance (ANOVA); ${ }^{*} \mathrm{P}<0.05,{ }^{* *} \mathrm{P}<0.01$.

mixtures were pipetted onto the comet assay slides. The cells were lysed by incubation of the mixture at $4^{\circ} \mathrm{C}$ for $3 \mathrm{~h}$, and the treated cells were then electrophoresed at $4^{\circ} \mathrm{C}$ for $20 \mathrm{~min}$. Subsequently, the resolved samples were fixed and the DNA was visualized by staining with $5 \mu \mathrm{g} / \mathrm{ml}$ GoldView (SBS Genetech, Co., Ltd., Beijing, China). The slides were observed under a confocal laser microscope, and digital fluorescence images were obtained to calculate the percentage of comet tails/100 cells.

Statistical analysis. SAS 8.1 was used to analyze the experimental data, which are presented as the mean \pm SD. The RT-qPCR, CCK-8, flow cytometry and comet tail percentage data, were analyzed using analysis of variance (ANOVA). The data from the clonogenic survival assay were analyzed using GraphPad Prism 5.0 software. Statistical significance was set at a $\mathrm{P}$-value of $<0.05$.

\section{Results}

Identification of GSC. In our previous study, we successfully identified GSCs using characteristics such as surface molecules, multipotency and tumorigenicity (5). In the present study, GSCs of both non-transfected and siRNA-ATM-transfected cells were found to form neurospheres composed of 3-5 cells and grown in bulk over $\sim 1$ week (Fig. 1A). In siRNA-ATM GSCs, the green fluorescence protein was also observed as in GCs (Fig. 1B). After GSCs from the U251 and A172 cell lines (including transfected cells) were induced, CD133 and nestin, surface molecules of GSC were detected in the neurospheres (Fig. 1C).
Changes in the expression of ATM after siRNA treatment. We examined the expression of the ATM gene and protein to assess the efficiency of siRNA-ATM in GSCs of the two cell lines using RT-qPCR (Fig. 2A) and western blotting. In GSCs, ATM expression was obviously downregulated via the transfection of siRNA-ATM packaged in the lentiviral vector. The PCR results of both $\mathrm{U} 251$ and A172 GSCs revealed that the ATM expression in the $\mathrm{C}$ and $\mathrm{N}$ groups was obviously increased post- vs. pre-irradiation $(\mathrm{P}<0.01)$. However, there was little increase in the ATM expression in the A group after irradiation $(\mathrm{P}<0.05)$. Moreover, ATM gene expression was considerably lower in the A group than in the $\mathrm{C}$ or $\mathrm{N}$ groups after irradiation $(\mathrm{P}<0.01)$ (Fig. 2B).

Similar results were observed from the western blot analysis of the U251 (Fig. 3A) and A172 GSCs (Fig. 3B). In the $\mathrm{C}$ and $\mathrm{N}$ groups, the total ATM protein level increased only slightly after vs. before irradiation. Surprisingly, although the expression of the phosphorylated-ATM (p-ATM) protein was slight pre-irradiation, it was obviously higher after irradiation (Fig. 3A and B). In the A group, the expression of total ATM protein was similarly low pre- and post-irradiation, but the p-ATM protein was not obviously expressed at the same treatment condition. After irradiation, the total ATM protein and $\mathrm{p}$-ATM protein in the A group exhibited lower expression than those in the $\mathrm{C}$ and $\mathrm{N}$ groups (Fig. 3A and $\mathrm{B}$ ).

$C C K-8$ assay. Cell proliferation of the A group in the two GSCs was significantly lower than those of the $\mathrm{C}$ and $\mathrm{N}$ groups at 48 and $72 \mathrm{~h}$ after irradiation (U251, $\mathrm{P}<0.01 ; \mathrm{A} 172, \mathrm{P}<0.01$, A group vs. $\mathrm{N}$ group; $\mathrm{P}<0.05$, A group vs. $\mathrm{C}$ group) (Fig. $4 \mathrm{~A}$ and $\mathrm{B}$ ). In the 
A
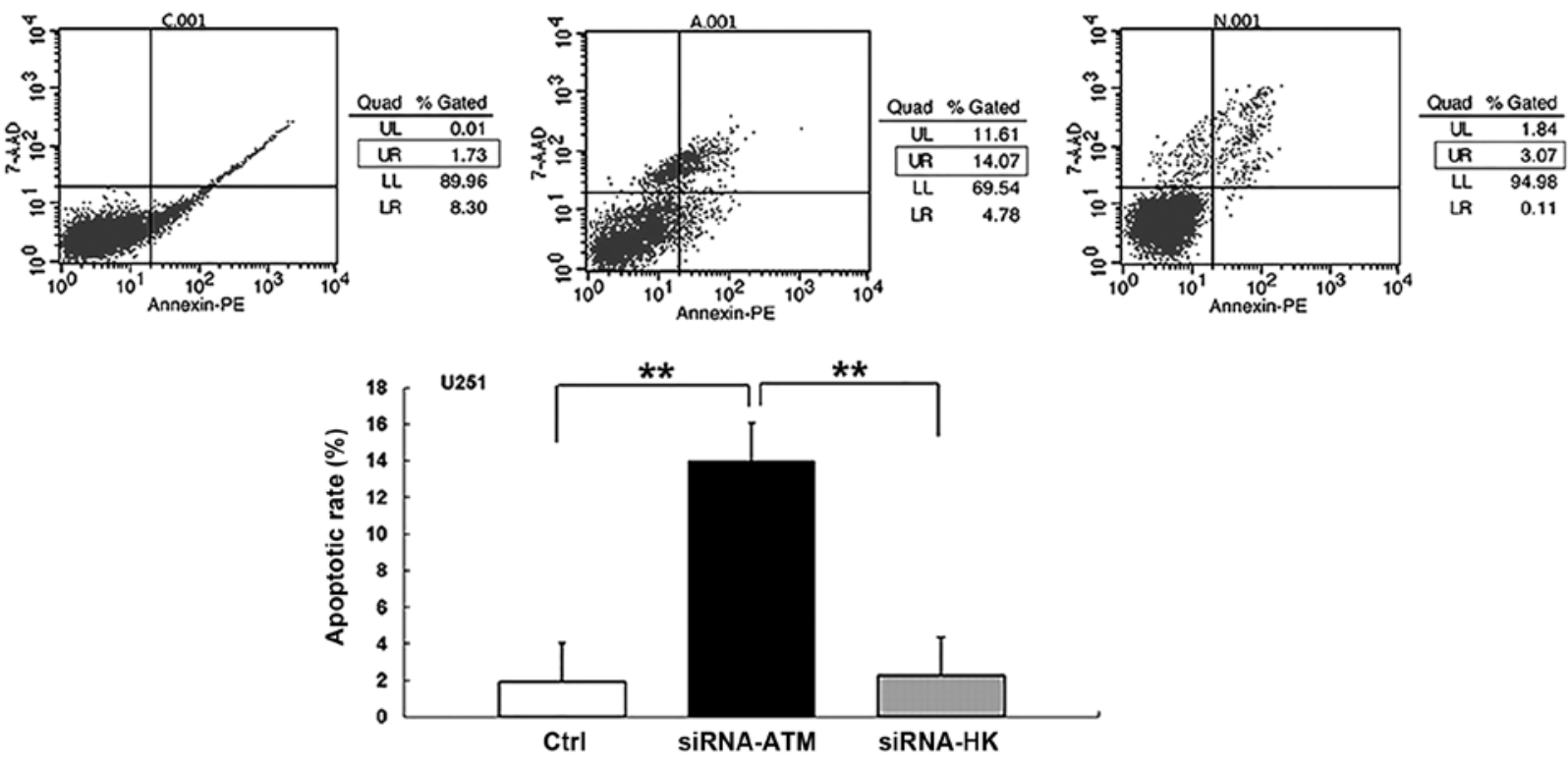

B
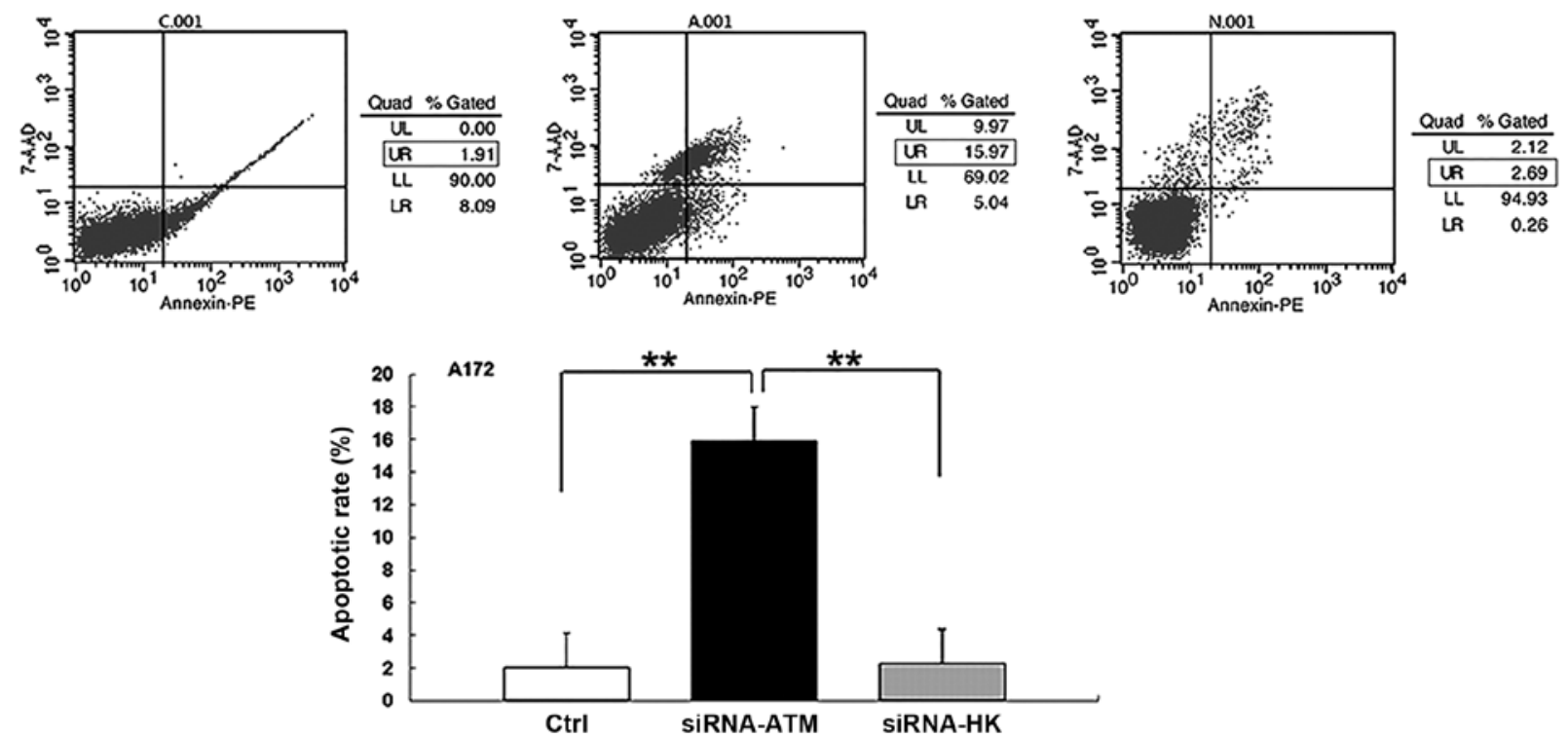

Figure 5. Cell apoptosis in U251 and A172 glioma stem cells is detected by flow cytometry. The cell apoptosis percentage of the late apoptosis stage in the A group was more significant than those in the C and N groups. (A) Data in U251 glioma stem cells. (B) Data in A172 glioma stem cells. Data were analyzed using analysis of variance (ANOVA); ${ }^{* *} \mathrm{P}<0.01$.

U251 GSCs, there was no obvious increase in cell proliferation in the A group between the two time-points. However, cell proliferation in the $\mathrm{C}$ and $\mathrm{N}$ groups mildly increased from 48 to $72 \mathrm{~h}$ ( $\mathrm{P}>0.05)$ (Fig. 4A). In the A172 GSCs, the cell proliferation in the A group between 48 and $72 \mathrm{~h}$ was mildly increased, but not significantly different. Meanwhile, there was a significant difference in the cell proliferation number in the $\mathrm{C}$ and $\mathrm{N}$ groups $(\mathrm{P}<0.01)$ (Fig. 4B).

Cell apoptosis and 62 phase block by flow cytometry. In GSCs from both cell lines, the percentage of apoptotic cells of the latter cell cycle stages was greater in group A than that in groups $\mathrm{C}$ and $\mathrm{N}(\mathrm{P}<0.01)$ (Fig. 5A and $\mathrm{B})$. There was no significant difference in the apoptosis rate between the $\mathrm{C}$ and $\mathrm{N}$ groups. Similarly, the percentage of blocked cells in the $\mathrm{G} 2$ phase in group A exhibited an obvious increase compared with those of groups $\mathrm{C}$ and N in U251 and A172 GSCs $(\mathrm{P}<0.01)$ (Fig. 6A and B).

Colony-forming assay. The number of formed colonies decreased as radiation dose increased in the three groups (C, A and N), which indicated a dose-dependent correlation in U251 and A172 GSCs (Fig. 7A). At the same dose, the number of colonies in the A group was less than those in the $\mathrm{C}$ and $\mathrm{N}$ groups, while the number of colonies were similar in the C and $\mathrm{N}$ groups in U251 and A172 GSCs (Fig. 7B). Microscopic observation after crystal violet staining revealed that the colonies formed by cells of the A group were smaller and lesser in both GSCs (Fig. 7C and D) after radiation with a 6 Gy dose. 
A
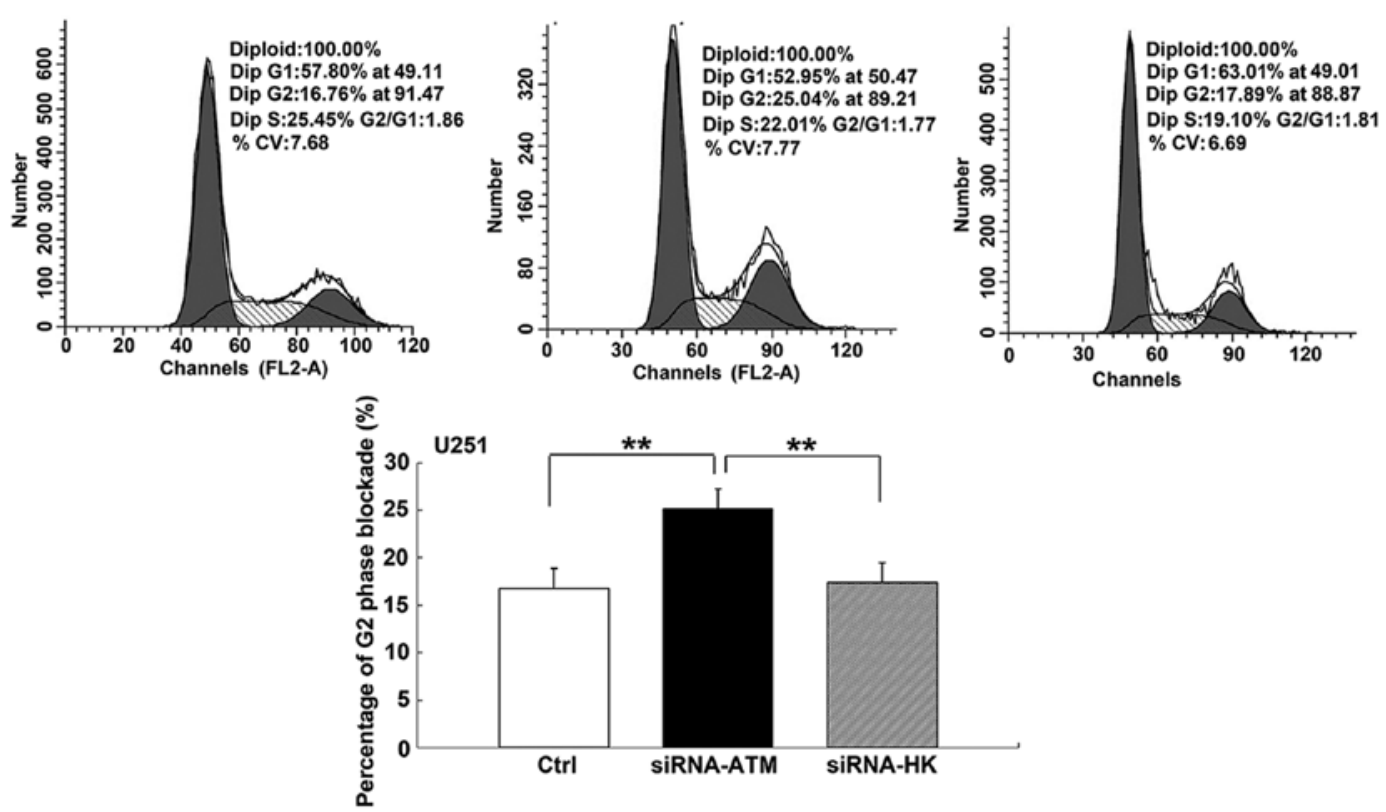

B
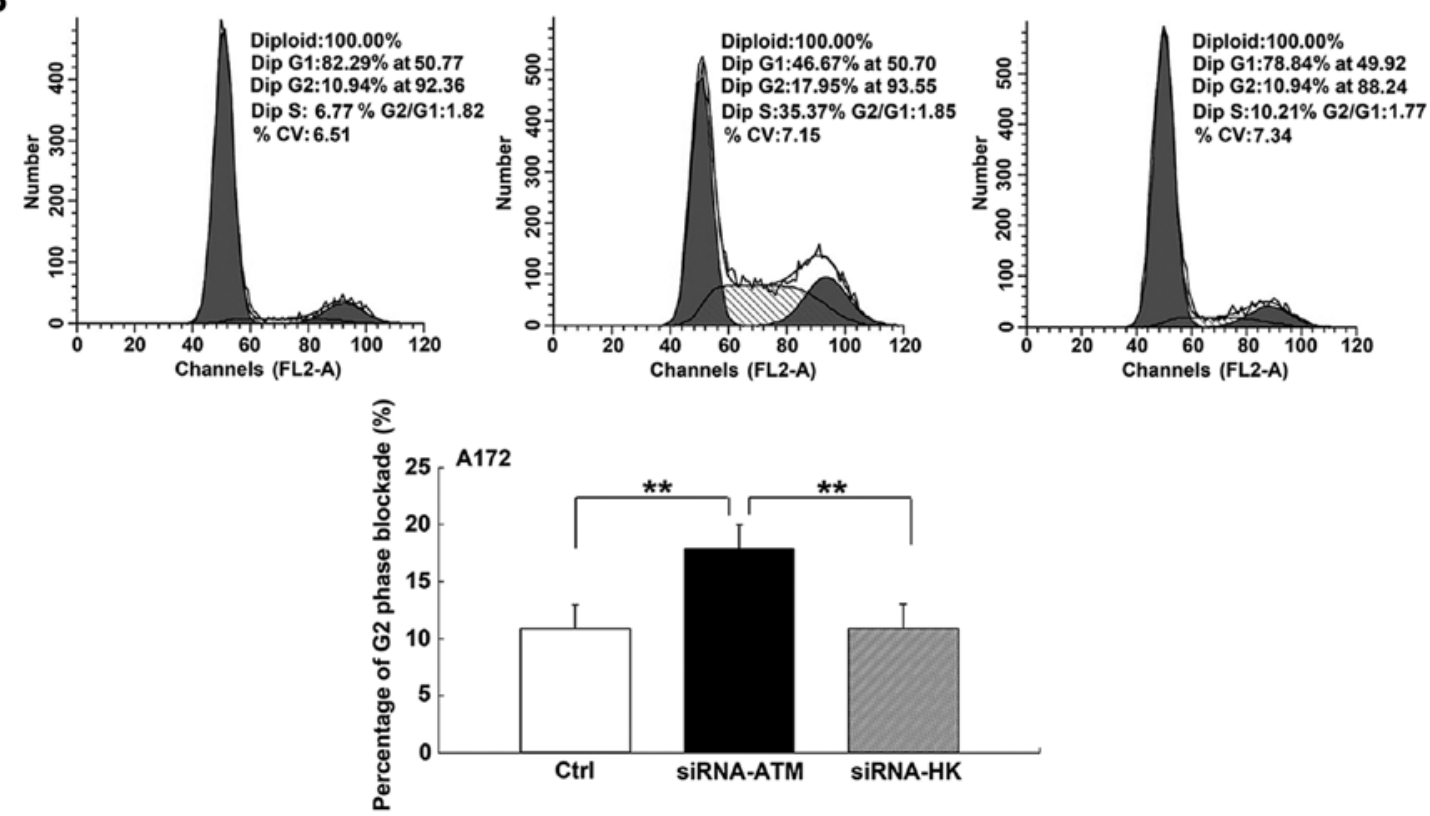

Figure 6. Cell distribution in the G2 phase under different conditions as determined by flow cytometry. The number of cells in the G2 phase in group A was obviously higher than those in the $\mathrm{C}$ and $\mathrm{N}$ groups of U251 and A172 glioma stem cells [** $\mathrm{P}<0.01$; analysis of variance (ANOVA)]. (A) Data in U251 glioma stem cells. (B) Data in A172 glioma stem cells.

Neutral comet assay. The neutral comet assay was performed to assess the level of double DNA damage in GSCs from both cell lines. Before irradiation, comet tail formation was not observed in any of the three groups. However, the percentage of comet tails in the A group was increased after irradiation with a 5 Gy X-ray dose compared with those in the $\mathrm{C}$ and $\mathrm{N}$ groups $(\mathrm{P}<0.01)$ (Fig. 8). The results in the $\mathrm{C}$ group were similar to those in the $\mathrm{N}$ group after the radiation treatment.

Changes in the expression of other radiosensitivity-related genes after transfection of the siRNA-ATM lentivirus into GSCs from the two cell lines. The expression levels of the radiosensitivity-related genes p53, proliferating cell nuclear antigen (PCNA), and survivin were also examined in both
GSCs using RT-qPCR. After irradiation, the expression levels of the three genes (p53, PCNA and survivin) increased to some degree in the $\mathrm{C}$ and $\mathrm{N}$ groups but were decreased in the A group $(\mathrm{P}<0.01)$. The expression of those genes in the A group was obviously less than those in the $\mathrm{C}$ and $\mathrm{N}$ groups after irradiation $(\mathrm{P}<0.01)$. The results between the U251 GSCs (Fig. 9A) and A172 GSCs (Fig. 9B) were similar.

Histopathology. In the U251 and A172 animal models using GSCs, the histopathological results differed before vs. after irradiation therapy. Before irradiation, the histopathology of glioma tumors was characterized by nuclear polymorphism, nuclear hyperchromatism and considerable karyokinesis, and the histological features of group A were similar to those 

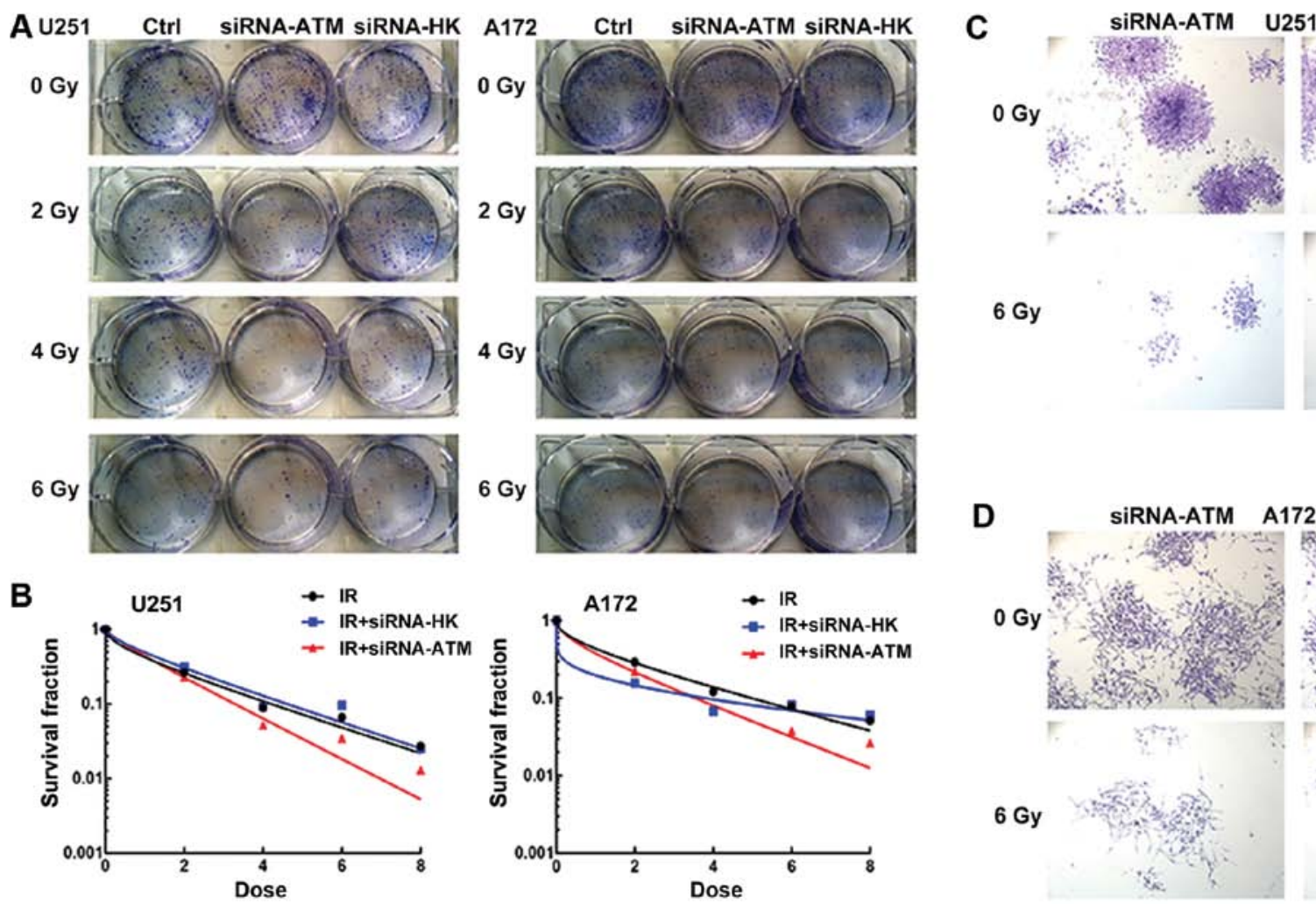

SiRNA-HK

$4 \mathrm{~Gy}$

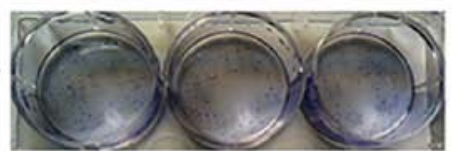

6 Gy
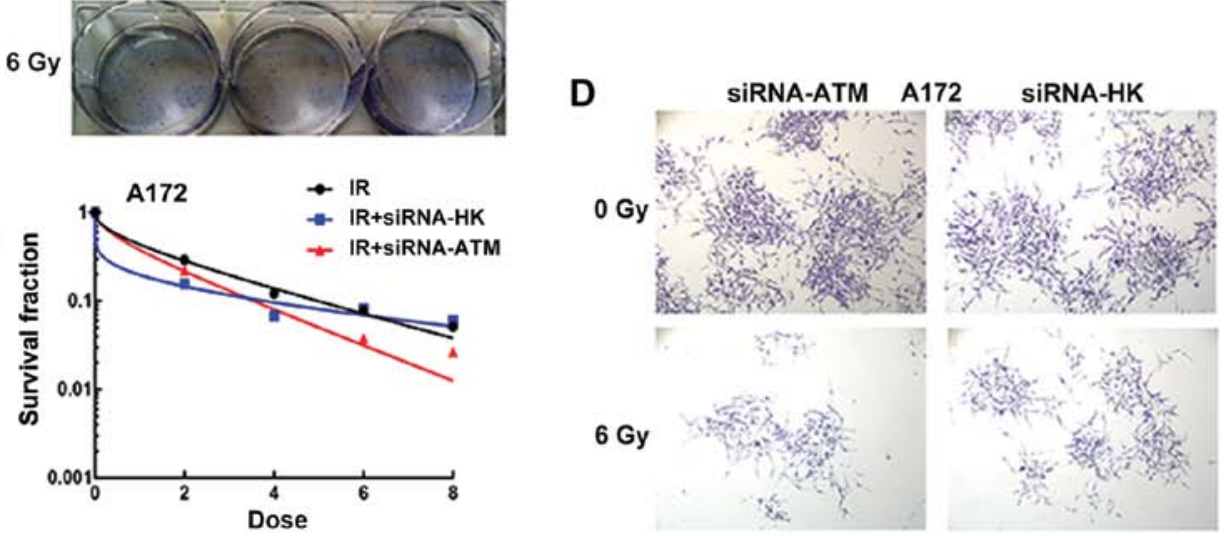

Figure 7. Clonogenic survival assay of small interfering RNA-ataxia-telangiectasia mutated (siRNA-ATM)-transfected glioma stem cells (GSCs). (A) The colony formation count in the $\mathrm{C}$, A and $\mathrm{N}$ groups in 6-well plates. (B) The survival fraction in the IR + siRNA-ATM group was much lower than those in other groups at doses of 2, 4, 6 and $8 \mathrm{~Gy}$. (C and D) Histopathological features revealed that the cell colonies of the siRNA-ATM-transfected GSCs were smaller in size and fewer in number than the non-transfected ones after irradiation.
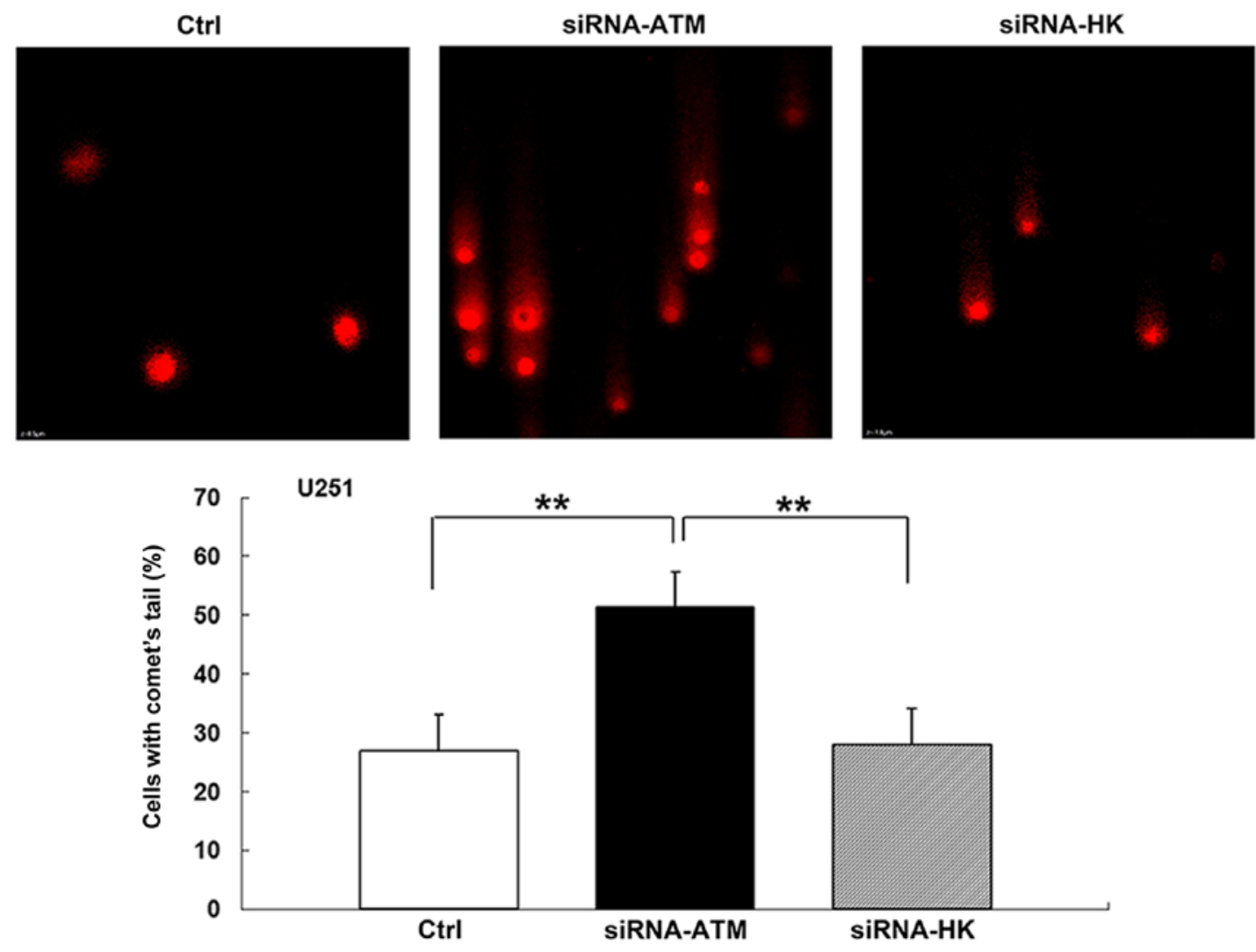

Figure 8. DNA damage in the U251 glioma stem cells after small interfering RNA-ataxia-telangiectasia mutated (siRNA-ATM) treatment after irradiation. More cells had comet tails in the A group than in the $\mathrm{C}$ and $\mathrm{N}$ groups $\left[{ }^{* *} \mathrm{P}<0.01\right.$; analysis of variance (ANOVA)]. 
A $\quad \mathrm{p} 53$

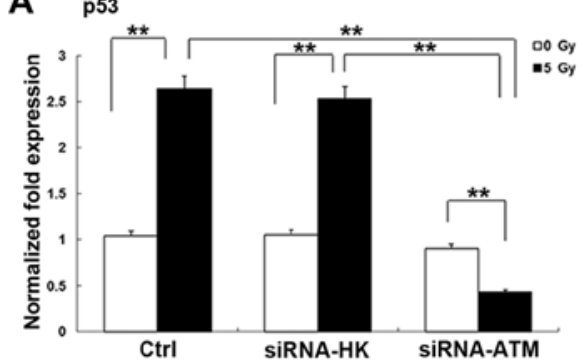

B $\quad \mathrm{p} 53$

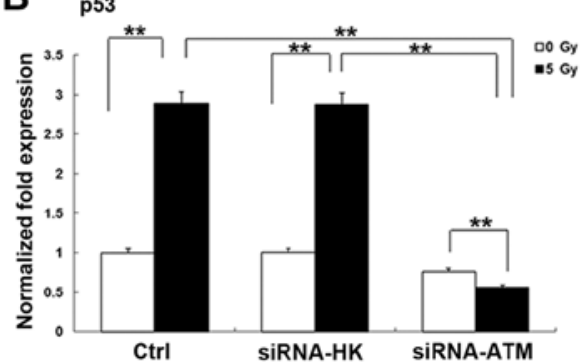

PCNA

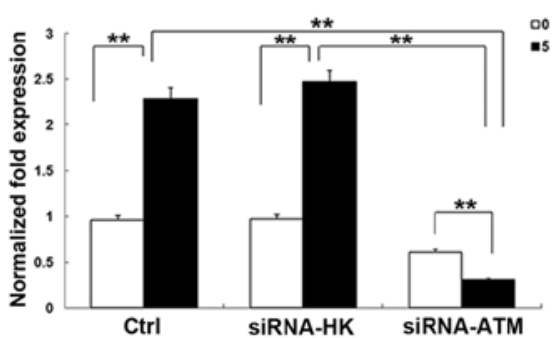

PCNA

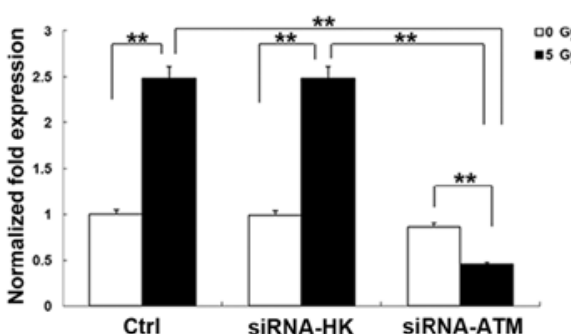

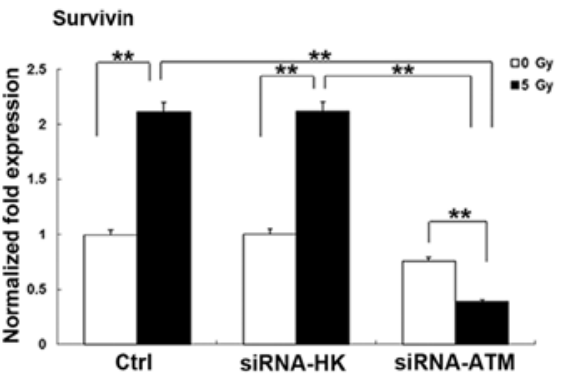

Survivin

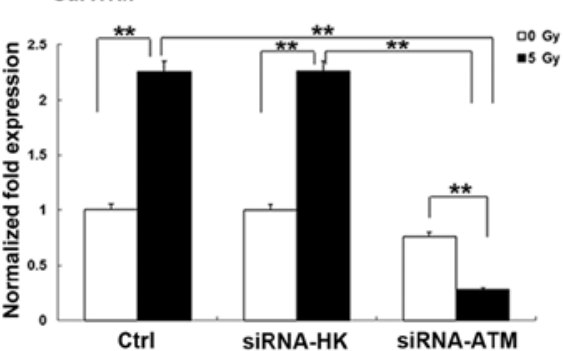

Figure 9. Expression of the radiosensitivity-related genes p53, proliferating cell nuclear antigen, and survivin in the U251 and A172 glioma stem cells as determined by reverse transcription quantitative polymerase chain reaction. There was no obvious inter-group difference pre-irradiation. Post-irradiation, expression of the three genes was considerably lower in the A group than in the $\mathrm{C}$ and $\mathrm{N}$ groups. All of the experiments were performed in triplicate. (A) Data in U251 glioma stem cells. (B) Data in A172 glioma stem cells. Data were analyzed using analysis of variance (ANOVA) and are presented as the mean \pm SD; ${ }^{* *} \mathrm{P}<0.01$.

A

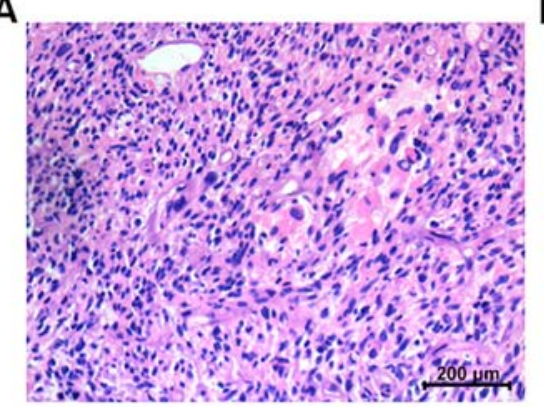

C

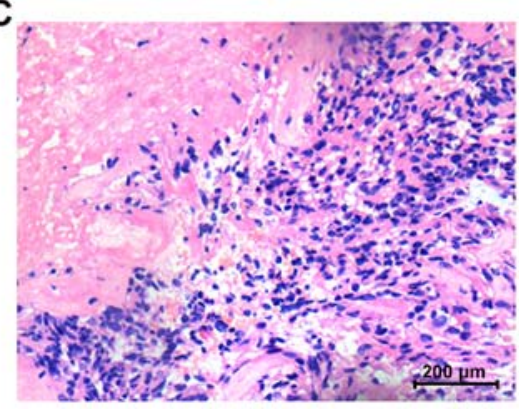

B

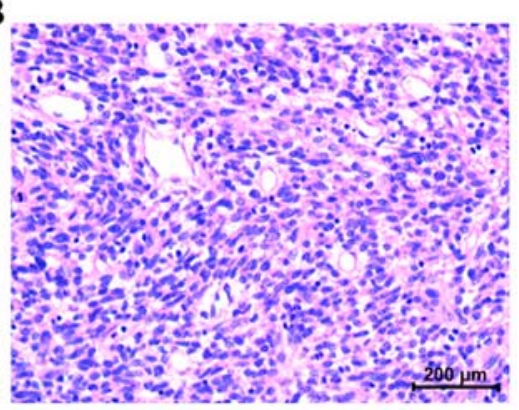

D

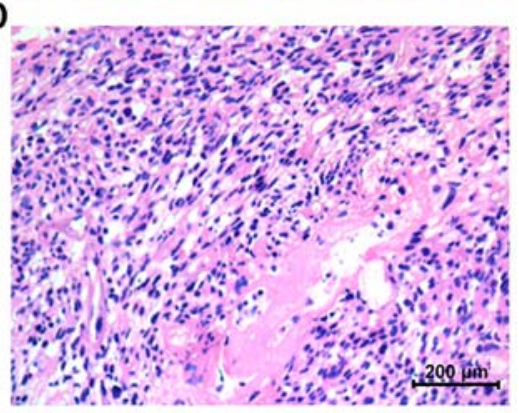

Figure 10. Histopathological findings in the small interfering RNA-ataxia-telangiectasia mutated (siRNA-ATM ${ }^{\text {Puro }}$ ) and siRNA-HK ${ }^{\text {Puro }}$ animal models treated with 15 Gy X-ray. (A and B) With pre-irradiation there was no obvious difference in the pathological characteristics between the A and N groups. (C and D) The degrees of necrosis and hemorrhage of the tumor cells in the (C) A group post-irradiation were greater than those in the (D) $\mathrm{N}$ group.

of group $\mathrm{N}$ (Fig. 10A and B). However, after irradiation, the necrosis and hemorrhage of the solid tumor tissue in group $\mathrm{A}$ were more obvious than that in group N (Fig. 10C and D).

\section{Discussion}

In recent years, GSCs, which play an important role in the radioresistance of glioma, have captured the attention of many scholars in the field of oncology (15-17). GSCs constitute a minor proportion of tumor cells that differ from glioma cells. Between tissues of different origins, there are marked differences in the DNA damage signaling pathways (18). It remains unclear whether the expression and regulation of some genes in GSCs differ from those in GCs.

In our previous study, we compared the radiosensitization of GSCs and GCs and found that ATM exhibited a high expression, which was linked to stronger radioresistance in GSCs than in GCs (5). Various studies confirmed that suppression of 
the ATM gene, which exhibited a high expression after radiation in glioma, contributed to the radiosensitivity of glioma. The current strategy mainly used includes gene interference and pharmacological inhibition $(8,15)$. Both ATM inhibition methods may specifically sensitize GSCs to DSB induced by radiation while sparing non-stem cells (15).

In the present study we employed two glioma cell lines of different origin and further induced GSCs from those cell lines for the subsequent experiments. Silencing of the ATM gene contributes to changes in the downstream signaling pathway, which thereafter affects GSC tumor behavior (19).

Genes related to radiosensitivity, including p53, survivin and PCNA, that are downstream of ATM (20-24) were analyzed using RT-qPCR. The results revealed that those genes (p53, survivin and PCNA) were indeed involved in the cell repair pathway. However, due to ATM silencing, the weakening of the repair effect plays a role in the radiosensitivity of glioma cells. These findings are consistent with those obtained from the CCK- 8 and colony formation assays, in which proliferation was also decreased in response to ATM silencing.

The colony forming and comet tail assays are the classic experiments for detecting the extent of DSB impairment. Combining radiation with ATM-gene expression inhibition increased the GSC damage. After irradiation, the survival fraction of the siRNA-ATM group was decreased compared with the control groups. Physical damage and breakage of DSB in the siRNA-ATM group increased significantly as well. These results all indicate that ATM gene inhibition caused GSC radiosensitivity.

The CCK-8 results revealed that the high expression of ATM after irradiation in untreated cells was responsible for repairing damaged cells and maintaining cell proliferation. However, the cell repair may have been slow, resulting in decreased cell proliferation when the ATM gene was interfered with. To determine whether proliferation is related to time requires further exploration. Notably, the A172 GSCs exhibited slower proliferation than the U251 GSCs. These two cell lines are derived from different individuals with many genetic differences, which may likely influence the response to irradiation (1).

Cell apoptosis or the percentage of G2 phase blockade by flow cytometry was also used to evaluate the cell damage. We found that the apoptosis rate of the latter stages and the percentage of G2 phase blockade in siRNA-ATM-transfected GSCs increased after irradiation treatment. The results inferred that inhibition of the ATM gene in GSCs decreased cell repair, which in turn led to further cell damage.

Although, numerous studies on ATM interference have been reported, most failed to be confirmed by in vivo experiments (25). To the best of our knowledge, this is the first study on siRNA-ATM transfection in a mouse model in the field of GSC radiosensitivity. We implanted subcutaneous tumors with U251 siRNA-ATM GSCs followed by irradiation therapy and found obvious tumor hemorrhaging and necrosis upon microscopic examination. The results in vivo explained that silencing the ATM gene, which plays an important role in cell proliferation and apoptosis, could affect the biological behavior of glioma tumors. However, the related mechanism of the siRNA-ATM transfection effect on tumor behavior requires further exploration. To simulate the therapeutic effect in this study, we intend to construct an orthotopic glioma mouse model in the future. However, dilemmas such as the need to construct a larger animal model and side-effects of radiation on the brain have yet to be overcome and need to addressed in the future.

The present study, demonstrated that the proliferation, colony formation rate and the survival fraction were decreased the most, while the apoptotic rate, percentage of G2 phase block, and percentage of comet tail cells increased the most after ATM gene inhibition followed by irradiation in GSCs. The data partly revealed similarities with other scholars that have examined glioma tumors $(1,2,9)$. We concluded that silencing the ATM gene in GSCs was a valuable strategy for enhancing the therapeutic effect thus, improving patient survival.

\section{Acknowledgements}

We thank the State Key Laboratory of Ultrasound Engineering in Medicine Co-Founded by Chongqing and the Ministry of Science and Technology for providing laboratory space. The present study was supported by the National Natural Science Foundation of China (no. 81172387), the Natural Science Foundation of Chongqing (cstc2015jcyjBX0060), and the Postgraduate Foundation of Chongqing (Xm2015086).

\section{References}

1. Biddlestone-Thorpe L, Sajjad M, Rosenberg E, Beckta JM, Valerie NC, Tokarz M, Adams BR, Wagner AF, Khalil A, Gilfor D, et al: ATM kinase inhibition preferentially sensitizes p53-mutant glioma to ionizing radiation. Clin Cancer Res 19: 3189-3200, 2013.

2. Wang SC, Wu CC, Wei YY, Hong JH and Chiang CS: Inactivation of ataxia telangiectasia mutated gene can increase intracellular reactive oxygen species levels and alter radiation-induced cell death pathways in human glioma cells. Int J Radiat Biol 87: 432-442, 2011.

3. Lomonaco SL, Finniss S, Xiang C, Decarvalho A, Umansky F, Kalkanis SN, Mikkelsen T and Brodie C: The induction of autophagy by gamma-radiation contributes to the radioresistance of glioma stem cells. Int J Cancer 125: 717-722, 2009.

4. Hambardzumyan D, Becher OJ, Rosenblum MK, Pandolfi PP, Manova-Todorova $\mathrm{K}$ and Holland EC: PI3K pathway regulates survival of cancer stem cells residing in the perivascular niche following radiation in medulloblastoma in vivo. Genes Dev 22: 436-448, 2008.

5. Zhou W, Sun M, Li GH, Wu YZ, Wang Y, Jin F, Zhang YY, Yang L and Wang DL: Activation of the phosphorylation of ATM contributes to radioresistance of glioma stem cells. Oncol Rep 30: 1793-1801, 2013.

6. Jackson SP: Sensing and repairing DNA double-strand breaks. Carcinogenesis 23: 687-696, 2002.

7. Knizhnik AV, Roos WP, Nikolova T, Quiros S, Tomaszowski KH, Christmann M and Kaina B: Survival and death strategies in glioma cells: Autophagy, senescence and apoptosis triggered by a single type of temozolomide-induced DNA damage. PLoS One 8: e55665, 2013.

8. Nadkarni A, Shrivastav M, Mladek AC, Schwingler PM, Grogan PT, Chen J and Sarkaria JN: ATM inhibitor KU-55933 increases the TMZ responsiveness of only inherently TMZ sensitive GBM cells. J Neurooncol 110: 349-357, 2012.

9. Gil del Alcazar CR, Hardebeck MC, Mukherjee B, Tomimatsu N, Gao X, Yan J, Xie XJ, Bachoo R, Li L, Habib AA, et al: Inhibition of DNA double-strand break repair by the dual PI3K/mTOR inhibitor NVP-BEZ235 as a strategy for radiosensitization of glioblastoma. Clin Cancer Res 20: 1235-1248, 2014. 
10. Golding SE, Rosenberg E, Adams BR, Wignarajah S, Beckta JM, O'Connor MJ and Valerie K: Dynamic inhibition of ATM kinase provides a strategy for glioblastoma multiforme radiosensitization and growth control. Cell Cycle 11: 1167-1173, 2012.

11. Raso A, Vecchio D, Cappelli E, Ropolo M, Poggi A, Nozza P, Biassoni R, Mascelli S, Capra V, Kalfas F, et al: Characterization of glioma stem cells through multiple stem cell markers and their specific sensitization to double-strand break-inducing agents by pharmacological inhibition of ataxia telangiectasia mutated protein. Brain Pathol 22: 677-688, 2012

12. Finnegan EJ and Matzke MA: The small RNA world. J Cell Sci 116: 4689-4693, 2003.

13. Chuah TL, Walker DG, Wei M, Scott S and Lavin MF: Approaches to sensitizing glioblastoma to radiotherapy: Use of lentiviral vectors. Int J Oncol 40: 1963-1969, 2012

14. Guha C, Guha U, Tribius S, Alfieri A, Casper D, Chakravarty P, Mellado W, Pandita TK and Vikram B: Antisense ATM gene therapy: A strategy to increase the radiosensitivity of human tumors. Gene Ther 7: 852-858, 2000.

15. Vecchio D, Daga A, Carra E, Marubbi D, Baio G, Neumaier CE Vagge S, Corvò R, Pia Brisigotti M, Louis Ravetti J, et al: Predictability, efficacy and safety of radiosensitization of glioblastoma-initiating cells by the ATM inhibitor KU-60019. Int J Cancer 135: 479-491, 2014.

16. Clarke MF, Dick JE, Dirks PB, Eaves CJ, Jamieson CH, Jones DL, Visvader J, Weissman IL and Wahl GM: Cancer stem cells - perspectives on current status and future directions: AACR Workshop on cancer stem cells. Cancer Res 66: 9339-9344, 2006

17. Golestaneh AF, Atashi A, Langroudi L, Shafiee A, Ghaemi N and Soleimani M: miRNAs expressed differently in cancer stem cells and cancer cells of human gastric cancer cell line MKN-45. Cell Biochem Funct 30: 411-418, 2012.
18. Moschos SJ, Dodd NR, Jukic DM, Fayewicz SL, Wang X and Becker D: Suppressing the high-level expression and function of ATM in advanced-stage melanomas does not sensitize the cells to ionizing radiation. Cancer Biol Ther 8: 1815-1825, 2009.

19. Squatrito M, Brennan CW, Helmy K, Huse JT, Petrini JH and Holland EC: Loss of ATM/Chk2/p53 pathway components accelerates tumor development and contributes to radiation resistance in gliomas. Cancer Cell 18: 619-629, 2010.

20. Burdak-Rothkamm S and Prise KM: New molecular targets in radiotherapy: DNA damage signalling and repair in targeted and non-targeted cells. Eur J Pharmacol 625: 151-155, 2009.

21. Zhang XD, Qin ZH and Wang J: The role of p53 in cell metabolism. Acta Pharmacol Sin 31: 1208-1212, 2010.

22. Poosarla C, Ramesh M, Ramesh K, Gudiseva S, Bala S and Sundar M: Proliferating cell nuclear antigen in premalignancy and oral squamous cell carcinoma. J Clin Diagn Res 9: ZC39-ZC41, 2015.

23. Yang M, Zhai X, Xia B, Wang Y and Lou G: Long noncoding RNA CCHE1 promotes cervical cancer cell proliferation via upregulating PCNA. Tumour Biol 36: 7615-7622, 2015.

24. Tamm I, Wang Y, Sausville E, Scudiero DA, Vigna N, Oltersdorf T and Reed JC: IAP-family protein survivin inhibits caspase activity and apoptosis induced by Fas (CD95), Bax, caspases, and anticancer drugs. Cancer Res 58: 5315-5320, 1998.

25. Ma X, Yang L, Xiao L, Tang M, Liu L, Li Z, Deng M, Sun L and Cao Y: Down-regulation of EBV-LMP1 radio-sensitizes nasal pharyngeal carcinoma cells via NF- $\kappa$ B regulated ATM expression. PLoS One 6: e24647, 2011. 